\title{
28 Research Square \\ Distribution of Hepatitis B Genotypes Among Hepatitis B Patients Visiting Decode Genomics Research Center
}

Gaurab Pandey ( $\sim$ pandeygaurab67@gmail.com )

Nobel College Pvt Ltd

Bibek Bogati

Nobel College Pvt Ltd

Sangam Shrestha

Nobel College Pvt Ltd

\section{Research Article}

Keywords: Hepatitis B, Hepatitis B virus, genotypes, PCR, Nepal

Posted Date: July 1st, 2021

DOI: https://doi.org/10.21203/rs.3.rs-674606/v1

License: (c) (i) This work is licensed under a Creative Commons Attribution 4.0 International License.

Read Full License 


\section{Abstract}

The hepatitis B virus (HBV) is non-cytopathic, hepatotropic and enveloped virus which causes Hepatitis B and infects the liver causing inflammation and hepatocellular necrosis. The genome sequence database shows that HBV has ten genetic diversities (A-J) ten in which the HBV genotypes, I and $\mathrm{J}$ are the new one. Three major genotypes of HBV (A, C and D) were found in Nepal. Despite being a low prevalence, Nepal has a diversity of hepatitis $B$. Hence, the study aims to determine the distribution of hepatitis $B$ genotypes among the hepatitis B patients visiting Decode Genomics Research Center. HBV genotypes were determined by using a simpler, more rapid, and more specific genotyping system for HBV involving PCR using type-specific primers. Our study showed that different HBV genotypes were identified in which genotype $D$ to be predominant one followed by $C$ and also showed presence of genotype $A, B$ and $F$. Many recombinant genotypes were also present in our study.

\section{Introduction}

The hepatitis B virus (HBV) is a small DNA containing, non-cytopathic, hepatotropic and enveloped virus (Liang, 2009; WHO, 2015). Its infection is known as hepatitis B and clinical manifestation is shown in liver causing inflammation and hepatocellular necrosis. HBV infection can be either acute or chronic, and may range from mild disease or asymptomatic infection to severe (WHO, 2015). Progression of chronic hepatitis B (CHB) disease to severe liver diseases, such as liver cirrhosis (LC) and hepatocellular carcinoma (HCC), is determined by the host's genetic characteristics, as well as by environmental and viral factors (Sunbul, 2014).

The genome sequence data base showed that HBV has been differentiated into ten genotypes (A-J) in which genotype I and $\mathrm{J}$ are the newer one (Sunbul, 2014). HBV genotypes have specific geographical distribution patterns (Kyaw et al., 2020). Genotype A is common place in Europe, Africa and India. Most of the HBV genotype $B$ and $C$ are from Asia including China, Japan and Indonesia. The genotype $D$ is common in the Mediterranean, Middle East, Pakistan and India region. The genotype $E$ is found in subSaharan Africa and India (Kumar et al., 2011). Genotype F is found in South and Central America (Croagh et al., 2015). Genotype I was reported in Vietnam and Laos. The newest genotype of HBV, genotype J, was been identified at Japan's Ryukyu Islands (Sunbul, 2014).

The prevalence report for distribution of different genotypes of HBV in Nepal is scanty. The 2012 report showed that there was a marked low prevalence of HBV (0.9\%) compared to China (10\%) and India (5\%) (Shrestha et al., 2012). The low prevalence may be because of horizontal transmission mainly among adolescents, lack of vertical transmission in early childhood and low infection among pregnant women. This unique pattern of HBV distribution and transmission suggests a fourth pattern of CHB infection among Nepal's population with $\mathrm{HBeAg}(-)$, anti-HBe (+), normal ALT and low HBV-DNA levels. Most of cases of liver cirrhosis and hepatocellular carcinoma are related to hepatic vena cava disease in Nepal (Shrestha \& Shrestha, 2012). Similarly, a 2014 report presented genotype D, A, B and C/D recombinant in HBsAg positive patients. By using distance-matrix and neighbour-joining analyses after bootstrapping to 
1000 replicates phylogenetic trees were created. Genotype A, C, and D were found to be major HBV genotypes in Nepal (Paudel et al., 2014).

Despite being a low prevalence, Nepal has a diversity of hepatitis B genotypes and very few researches have been performed on hepatitis $B$ genotypes. Hence, this study was carried out to find out the viral load along with distribution of different HBV genotypes among Nepalese population visiting Decode Genomics and Research Centre (DGRC), Nepal.

\section{Materials And Methods}

This was a prospective type of study conducted from June 2017 to November 2017 in Decode Genomics and Research Centre (DGRC), Kathmandu, Nepal. All together 104 positive samples were taken from HBsAg positive patients visiting DGRC. The exclusion criteria were HIV positive cases, HBsAg negative cases and international patients. Blood sample had been collected on EDTA vial by following the standard procedure of blood collection (WHO, 2010). The viral DNA from blood samples had been extracted using SpinStar ${ }^{\text {TM }}$ Viral Nucleic Acid Extraction kit 1.0 following manufacturer protocol (Supplementary I). Viral load estimation on each blood samples had been done using RealStar® HBV PCR kit 1.0. (Supplementary II). The Hepatitis B genotypes A, B, C, D, E and F had been determined by PCR using type specific primers (Supplementary III). The detail for PCR time temperature relation is described elsewhere (Naito et al., 2001). The PCR product for the Genotyping had been analysed in $2 \%$ Agarose gel using standard protocol. DNA ladder of $100 \mathrm{bp}$ was used for this study. The ethical approval for this research project was approved from Institutional Review Committee Nobel College, National Ethical Guidelines for Health Research in Nepal (Reference number: NIRC 088/2017).

\section{Results}

A total of $104 \mathrm{HBsAg}$ positive serum samples were collected from patients visiting DGRC. Out of 104 patients enrolled for this study 67 were males and 37 were females. Age of the enrolled patients was from 19 year to 78 years.

Genotypes within HBV viral load

The highest viral load in our study was $>10$ million IU/ml which had genotype A whereas lowest viral load was $31 \mathrm{IU} / \mathrm{ml}$ had genotype $\mathrm{C}$. 
Table 1

HBV viral load and the predominant genotypes

\begin{tabular}{|llll|}
\hline HBV viral load & Number of & Genotypes & \\
\cline { 3 - 4 } & patients & Predominant & Others \\
\hline High $(>20000 \mathrm{IU} / \mathrm{mL})$ & 42 & C & A, D and other than A-F \\
\hline $\begin{array}{l}\text { Moderate } \\
(2000-20000 \mathrm{IU} / \mathrm{mL})\end{array}$ & 30 & D & C, other than A-F \\
\hline Low $(<2000 \mathrm{IU} / \mathrm{mL})$ & 32 & D & Other than A-F \\
\hline
\end{tabular}

HBV genotyping

Type-specific primers were used for HBV genotyping using nested PCR. Type specific primers were designed for the detection of conserved region of genotypes A, B, C, D, E and F. Out of 104 patients enrolled for the study HBV, Genotypes was determined in 57 patients while 47 patients had genotypes other than A-F. Among 57 patients, genotype $D$ was present in highest number (18 patients) followed by $C$ (14 patients), A (6 patients), B (2 patients) and Genotype $F$ was observed only in one patient. Genotype $E$ was not found in any patients enrolled for the study. Sample from 16 patients had found recombinant genotypes in which six recombinants were seen in our study viz. $B / C, B / C / D, C / D, A / C, C / F$ and $D / A$. The $C / D$ recombinant was the predominant one followed by $A / C, B / C / D$ and $D / A$ and their number was $7,3,2$ and 2 respectively. $B / C$ and $C / F$ recombinant was seen in 1 patient each. On contrary, 47 patients had genotypes other than A-F.

Sex wise HBV Genotypes Distribution Pattern

As shown in Fig. 2, out of 104 patients enrolled for the study, the number of male and female patients of different age groups were 67 and 37 respectively. Distribution of HBV genotypes was also uneven among different sex. Genotype $C$ was more common among male patients than genotype $D, A$ and $B$.

Recombinant genotypes were also high among male patients than female patients. Most of the female patients have genotype $D$, followed by $A, B, C, F$ and recombinants.

Age wise Distribution of HBV Genotype

The age wise distribution of genotypes is shown in Table 2 . 
Table 2

Age group and their genotypes.

\begin{tabular}{|llllllll|}
\hline Age Group & \multicolumn{7}{l|}{ HBV Genotypes } \\
\cline { 2 - 7 } & A & B & C & D & F & Recombinants & Unknown \\
\hline $\mathbf{0}-10$ & & & & & & & \\
\hline $11-20$ & 2 & 1 & 3 & 2 & & 2 \\
\hline $21-30$ & & & 2 & 7 & 6 & 6 \\
\hline $31-40$ & 1 & & 6 & 2 & 1 & 8 \\
\hline $\mathbf{4 1 - 5 0}$ & & 1 & 3 & 1 & 3 & 15 \\
\hline $\mathbf{5 1 - 6 0}$ & 2 & & 1 & 1 & 2 & 4 \\
\hline $\mathbf{6 1 - 7 0}$ & & & & 2 & 3 & 3 \\
\hline$>70$ & 1 & 1 & 1 & 1 & 1 & \\
\hline
\end{tabular}

\section{Discussion}

Three major genotypes of HBV in Nepal were found to be A, C and D. Despite being a low prevalence, Nepal has a diversity of hepatitis B genotypes (Paudel et al., 2014). The result of our study showing the predominance of genotype D agrees with the report from Shrestha et al. (2012) who had reported the predominant HBV genotypes in Nepal included D followed by A. Similarly, the dominance of Genotype D in Nepal was reported by Paudel et al. (2014) which agrees with our study that Genotype D was found predominant. In our study the recombinant genotype C/D were predominant which shows agreement with Paudel et al. (2019) who had reported genotype A, B, C, D and recombinant genotype C/D in the locality of Nepal.

Hepatitis B genotyping is important for the clinical management of the disease, because HBV genotype is correlated with the replication of the virus, its activity in the liver and treatment outcome (Guettouche et al., 2005). All HBV genotypes have the potential to infect individuals, leading to chronic infection with various stages of progressive liver disease including cirrhosis and $\mathrm{HCC}$, and death. The rate of progression of disease and incidence of advanced liver disease may vary for each genotype of HBV and is influenced by environmental, host, and viral factors (Guettouche \& Hnatyszyn, 2005). HBV genotypes C and $D$ are generally associated with more severe liver diseases than $B$ and $A$, respectively. More serious liver disease in patients infected with HBV genotype B, including cirrhosis and HCC, than in patients with genotype $\mathrm{C}$. Individuals infected with HBV genotypes A or $\mathrm{C}$ were found to be more likely than patients exposed to genotypes $D$ and $B$ to progress to chronic hepatitis, however, all genotypes can lead to acute or chronic infections. The main therapeutic goal of HBeAg-negative, low or undetectable levels of HBV DNA and normal levels of alanine aminotransferase ( ALT) in patients with chronic hepatitis $B$ is the conversion from an active to an inactive carrier state (Guettouche \& Hnatyszyn, 2005). 


\section{Conclusion}

In conclusion, different genotypes have been identified in our study. The results from our study showed that genotype $D$ was found predominantly followed by $C$ whereas there were also presence of genotype $A$, $B$ and F. Many recombinant genotypes were also present in our study.

\section{Declarations}

- Ethics approval and consent to participate

Approved by the ethics committee.

- Consent for publication

"Not applicable"

- Availability of data and materials

"Not applicable"

- Competing interests

"The authors declare that they have no competing interests"

- Funding

No funding or grants. Self-funded.

- Authors' contributions

The work design was done by Gaurab Pandey and Sunil Prasad Lekhak. Gaurab Pandey, Bibek Bogati and Sangam Shrestha performed the study and got the results. The entire draft and final was prepared by Gaurab Pandey and is corresponding author. All authors read and approved the final manuscript.

\section{- Acknowledgements}

We owe our sincere and deepest gratitude to our supervisor Mr. Sunil Prasad Lekhak. This work would not have the spirit it has without the precious, lenient, merciful \& ever mesmerizing prolific, academic, practical, psychological \& moral support. Thank you so much for supporting and encouraging us to develop a new finding with our thesis work; providing critical guidance; suggesting for improvement during our entire dissertation \& cooperating with us according to the situations. We are also thankful to our internal supervisor Mr. Pramod Kumar Yadav. We are also very much grateful to our principal Mr. Kamal Prasad Regmi \& our Head of Department Mr. Khelananda Prasad Singh, Department of Laboratory medicine, all board members, B.Sc. MLT department \& Nobel College Library for their technical \& academic support in the due course of the study. We express our heartiest gratitude to Niroj Amatya (M. 
Sc. Microbiology-Medical) for valuable advice \& cordial cooperation admiration to complete this work. We are equally obliged to all of our colleagues of B.Sc. MLT, for their incessant \& unforgettable support in every pavement of student life.

At Decode Genomics \& Research center we wish to express our earnest appreciation \& thankful words to patient visiting DGRC for providing samples for our study. We would also like to thank Mr. Balram Gautam, Mr. Shree Ram Bastola and all staffs, employees \& other members for their support by providing us with necessary facilities, technical guidance \& creative environment during our research period.

From the very core of our heart, we are grateful to our parents who have always wished for us to blossom with every step we take in our present and pave our way to a brighter future. We would like to offer our gratitude to all of our teachers who have imparted us qualities of endurances, self-reliance \& compassion for humanity. To those we have named \& to those not recognized in spite of your support, we thank you all.

Sincerely,

Bibek Bogati

Gaurab Pandey

Sangam Shrestha

\section{References}

Croagh, C. M., Desmond, P. V., \& Bell, S. J. (2015). Genotypes and viral variants in chronic hepatitis B: A review of epidemiology and clinical relevance. World journal of hepatology, 7(3), 289.

Guettouche, T., \& Hnatyszyn, H. J. (2005). Chronic hepatitis B and viral genotype: the clinical significance of determining HBV genotypes. Antiviral Therapy, 10(5), 593.

Kumar, R., \& Singh, J. (2011). Genetic diversity of HBV genotypes/subgenotypes and their Correlation with disease progression. Euroasian Journal of Hepato-Gastroenterology, 1(2), 53-67.

Kyaw, Y. Y., Lwin, A. A., Aye, K. S., Thu, H. M., Htun, M. M., Soe, H. O., . . Cheong, J. (2020). Distribution of hepatitis $B$ virus genotypes in the general population of Myanmar via nationwide study. BMC infectious diseases, 20(1), 1-11.

Liang, T. J. (2009). Hepatitis B: the virus and disease. Hepatology, 49(S5), S13-S21.

Lindh, M., Gonzalez, J. E., Norkrans, G., \& Horal, P. (1998). Genotyping of hepatitis B virus by restriction pattern analysis of a pre-S amplicon. Journal of virological methods, 72(2), 163-174. 
Naito, H., Hayashi, S., \& Abe, K. (2001). Rapid and specific genotyping system for hepatitis B virus corresponding to six major genotypes by PCR using type-specific primers. Journal of clinical microbiology, 39(1), 362-364.

Paudel, D., Aung, M. N., Sa-nguanmoo, P., Suvedi, S., Paudel, A., Sharma, D., \& Poovorawan, Y. (2014). Diversity of Hepatitis B genotypes in Nepal and updated Phylogenetic Tree: a Pilot Survey in 2012. Journal of the Nepal Medical Association, 52(196).

Paudel, D., \& Suvedi, S. (2019). Hepatitis B Genotyping and Clinical Implication. In Hepatitis B and C. IntechOpen.

Shrestha, S. M., \& Shrestha, S. (2012). Chronic hepatitis B in Nepal: an Asian country with low prevalence of HBV infection. Tropical Gastroenterology, 33(2), 95-101.

Sunbul, M. (2014). Hepatitis B virus genotypes: global distribution and clinical importance. World journal of gastroenterology: WJG, 20(18), 5427.

WHO. (2010). WHO guidelines on drawing blood: best practices in phlebotomy. World Health Organization.

WHO. (2015). Guidelines for the prevention care and treatment of persons with chronic hepatitis $B$ infection: Mar-15: World Health Organization.

\section{Figures}

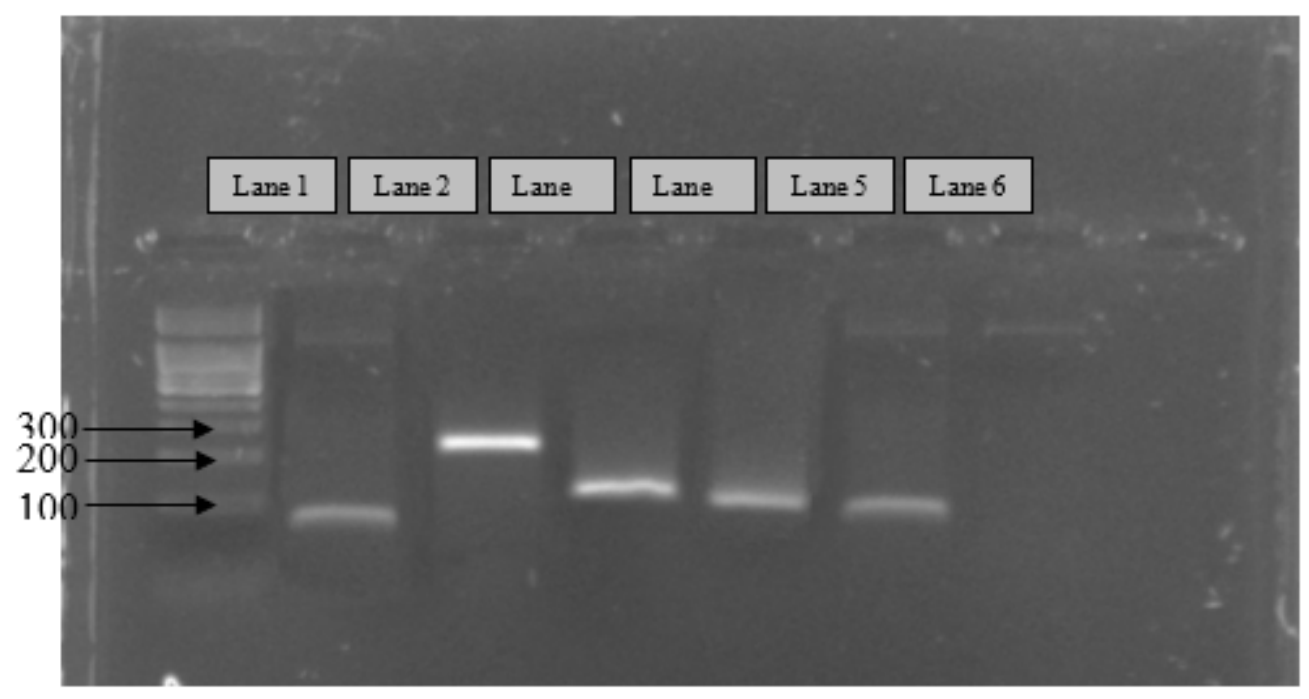

\section{Figure 1}

Gel Electrophoresis result showing different HBV genotypes. Lane 1-100bp ladder; lane 2- Genotype A (68 bp); lane 3- Genotype B (281 bp); lane 4- Genotype C (122 bp); lane 5- Genotype D (119 bp); lane 6Genotype F (97 bp). 


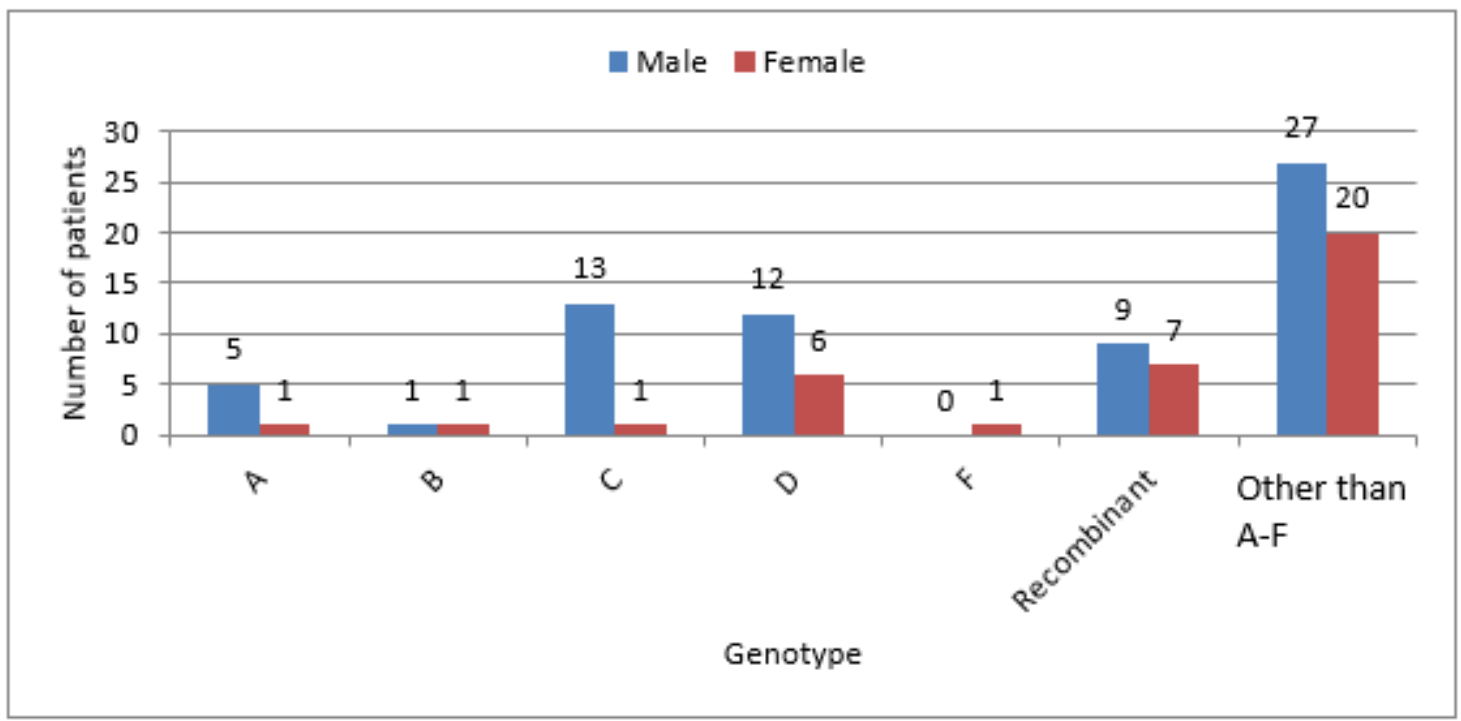

Figure 2

Graph showing sex wise distribution of hepatitis B genotypes in different sex.

\section{Supplementary Files}

This is a list of supplementary files associated with this preprint. Click to download.

- HBVGenotypessupplementary.docx 